\title{
EVALUATION OF COMPLICATIONS ASSOCIATED WITH TRANSFORAMINAL EPIDURAL STEROID INJECTION ADMINISTERED IN LUMBOSACRAL RADICULOPATHY
}

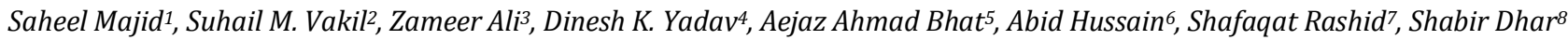

${ }^{1}$ Associate Professor, Department of Orthopaedics, SKIMS Medical College, Bemina, Srinagar, J \& K, India.

${ }_{2}^{2}$ Registrar, Department of Orthopaedics, SKIMS Medical College, Bemina, Srinagar, J \& K, India.

${ }^{3}$ Registrar, Department of Orthopaedics, SKIMS Medical College, Bemina, Srinagar, J \& K, India.

${ }^{4}$ Post Graduate, Department of Orthopaedics, SKIMS Medical College, Bemina, Srinagar, J \& K, India.

${ }^{5}$ Registrar, Department of Orthopaedics, SKIMS Medical College, Bemina, Srinagar, J \& K, India.

${ }^{6}$ Post Graduate, Department of Orthopaedics, SKIMS Medical College, Bemina, Srinagar, J \& K, India.

${ }_{7}^{7}$ Registrar, Department of Anaesthesiology, SKIMS Medical College, Bemina, Srinagar, J \& K, India.

${ }^{8}$ Assistant Professor, Department of Orthopaedics, SKIMS Medical College, Bemina, Srinagar, J \& K, India.

\section{ABSTRACT}

\section{BACKGROUND}

Lumbosacral radiculopathy is a common medical and socio-economic problem with a lifetime prevalence estimated to be around 40\%-60\%. Fluoroscopically guided transforaminal injection serve as an important tool in the nonsurgical management of lumbosacral radiculopathy secondary to herniated nucleus pulposus. This study was done in SKIMS Medical College, Srinagar, to evaluate the complications associated with the fluoroscopically-guided transforaminal epidural steroid injections.

\section{AIMS AND OBJECTIVES}

Evaluation of complications associated with Transforaminal Epidural Steroid Injection administered in Lumbosacral Radiculopathy.

\section{METHODS}

This prospective study was conducted in the Department of Orthopaedics, SKIMS Medical College and Hospital, Bemina, Srinagar, J \& K, India for a 2-year period from November 2012 to October 2014; 110 cases, both male and female in the age group of 20-60 years having back pain with radiculopathy of varied types and duration were enrolled in the study. After selecting a patient, transforaminal block was given using a spinal needle (20-25 Gauge) under fluoroscopic guidance. The complications if any were noted immediately and thereafter.

\section{CONCLUSIONS}

Transforaminal epidural steroid injections is an excellent form of conservative treatment in management of low back ache with radicular pain. It is relatively safe and simple, avoids risks and is associated with insignificant rate of complications which are minor in nature.

\section{KEYWORDS}

TFESI, ILESI, SNRB, SLRT.

HOW TO CITE THIS ARTICLE: Majid S, Vakil SM, Ali Z, et al. Evaluation of complications associated with transforaminal epidural steroid injection administered in lumbosacral radiculopathy. J. Evolution Med. Dent. Sci. 2016;5(27):1405-1409,

DOI: $10.14260 /$ jemds/2016/331

\section{INTRODUCTION}

In modern day society, one would be hard pressed to overestimate the impact of backache. Back pain combined with radicular pain remains one of the most challenging musculoskeletal problems for therapeutic management in modern society. ${ }^{1}$ This malady results from nerve root impingement and/or inflammation that causes neurologic symptoms in the distribution of the affected nerve $\operatorname{root}(\mathrm{s})$. Lumbosacral radiculopathy is a common medical and socioeconomic problem with a lifetime prevalence estimated to be around $40 \%-60 \% .2,3,4$ Patients with low back pain with or without radiation comprise a large proportion of referrals to specialists dealing with chronic back problems. In 1930,

Financial or Other, Competing Interest: None.

Submission 10-02-2016, Peer Review 11-03-2016,

Acceptance 17-03-2016, Published 04-04-2016.

Corresponding Author:

Dr. Suhail M. Vakil,

R/O: B-12, Budshah Nagar, Natipora,

Srinagar-190015, J\& K, India.

E-mail: suhailvakil1@yahoo.com

DOI: $10.14260 /$ jemds $/ 2016 / 331$
Evans reported that sciatica could be treated by epidural injection.

The use of epidural corticosteroid injection for the treatment of axial and radicular back pain was first reported in 1953.5 Lumbar Transforaminal Epidural Steroid Injections (TFESIs) are performed to provide symptomatic relief in patients with radicular pain.6,7 Radicular pain manifests when adhesions and inflammation in the epidural space stimulate nerve roots. Steroid containing injections are thought to reduce pain due to their anti-inflammatory properties and membrane stabilising effects. They have also been proved to be effective as a non-surgical option. 8,9

The goal is to deliver steroids and anaesthetics into the epidural space around the spinal nerves and other spinal structures. A transforaminal injection is an approach towards the epidural space via the intervertebral foramen where the spinal nerves exit.10,11,12,13 Fluoroscopically guided transforaminal injection serve as an important tool in the nonsurgical management of lumbosacral radiculopathy secondary to herniated nucleus pulposus. A Transforaminal Epidural Steroid Injection (TFESI) using a small volume of local anaesthetic will anaesthetize the spinal nerve and also 
partially anaesthetize the dura, the posterior longitudinal ligament, the intervertebral disc and facet joint. ${ }^{14}$

Since TFESI has become the preferred method of treatment of back pain with radiculopathy, it has become important to recognize the complications if any associated with this procedure and the effect of these complications. ${ }^{15,16,17,18,19,20,21,22}$

Arnold T Berman et al. (1984) studied the effects of epidural injection and local anaesthetics and corticosteroids in patients with lumbosciatic pain. They observed some complications such as transient hypotension, difficulty in voiding, severe paraesthesias, cardiac angina, sinus arrhythmias, respiratory difficulty and headache. Edith $\mathrm{R}$ Kepes and Derek Dun Calf (1985) found that the complications with the use of subarachnoid steroids are sufficiently serious that this form of therapy should be condemned.23,24 We did a study in SKIMS Medical College, Srinagar, to evaluate the complications associated with the fluoroscopically-guided transforaminal epidural steroid injections.

\section{AIMS AND OBJECTIVES}

Evaluation of complications associated with transforaminal epidural steroid injection administered in lumbosacral radiculopathy.

\section{MATERIALS AND METHODS}

This prospective study was conducted in the Department of Orthopaedics, SKIMS Medical College and Hospital, Bemina, Srinagar, J \& K, India, for a 2-year period from November 2012 to October 2014; 110 cases, both male and female in the age group of 20-60 years having back pain with radiculopathy of varied types and duration without neuro deficit were enrolled in the study.

The patients were assessed in terms of gait, posture, onset, duration, radiation and character of pain. The patients were subjected to thorough history, physical examination and a detailed neurological examination. The patients underwent various clinical tests followed by radiological investigations like X-rays and MRI to support our diagnosis, which was formulated on clinical basis. Patients also underwent tests like Bleeding Time (BT), Clotting Time (CT) to rule out any bleeding disorders. All these tests were done on OPD basis and the patients did not require hospitalisation. The required block was given in Operation Theatre under C-arm guidance.

\section{Inclusion Criteria}

1. Leg pain greater than back pain.

2. Symptoms greater than 6 weeks.

3. MRI documented herniated nucleus pulposus.

4. Less than $50 \%$ narrowing of the intervertebral foramen.

5. Constant radicular pain without sensory or motor deficit.

\section{Exclusion Criteria}

1. Back pain with neuro deficit.

2. Acute pain of less than 2 weeks' duration.

3. Any bleeding disorders.

4. Patient on anticoagulants.

5. Back pain due to massive disc.

6. Previous surgery.

7. Severe central or foraminal stenosis.

8. Progressive neuro deficit.

9. Prior epidural steroid injection.

\section{MATERIALS USED}

After selecting a patient for giving transforaminal block, we used a local anaesthetic (2\% Xylocaine).

Contrast media, e.g. Iohexol was used to demarcate the correct positioning of the needle. A spinal needle (20-25 gauge) and $5 \mathrm{~mL}$ syringe were used to deliver the drug.

\section{PROCEDURE}

The patient was placed prone on the radiolucent operative table. The area of injection was prepared with isopropyl alcohol and povidone-iodine several segments above and below the interspace to be injected. The patient was draped in a sterile fashion. Under antero-posterior fluoroscopic guidance, the target interspace was identified. The soft tissues over the lateral border and the midway between the two adjacent transverse processes at the target interspace were anaesthetized with Xylocaine 2\%. A 43/4 inch, 22-gauge spinal needle was taken and advanced within the anaesthetized soft tissue under fluoroscopy until contact was made with the lower edge of superior transverse process near its junction with superior articular process.

The spinal needle was retracted 2-3 $\mathrm{mm}$ and redirected towards the base of appropriate pedicle and advanced slowly to the 6'o clock position of the pedicle under fluoroscopy. The $\mathrm{C}$-arm was adjusted to the lateral position to confirm the position. Then we returned $\mathrm{C}$-arm to the AP view. The stylet was removed; $1 \mathrm{~mL}$ of non-ionic contrast was injected slowly to produce a perineurosheathogram. After an adequate dye pattern was observed, a $2 \mathrm{~mL}$ volume containing $1 \mathrm{~mL}$ of $2 \%$ preservative free Xylocaine and 1-2 $\mathrm{mL}$ of dexamethasone was injected.

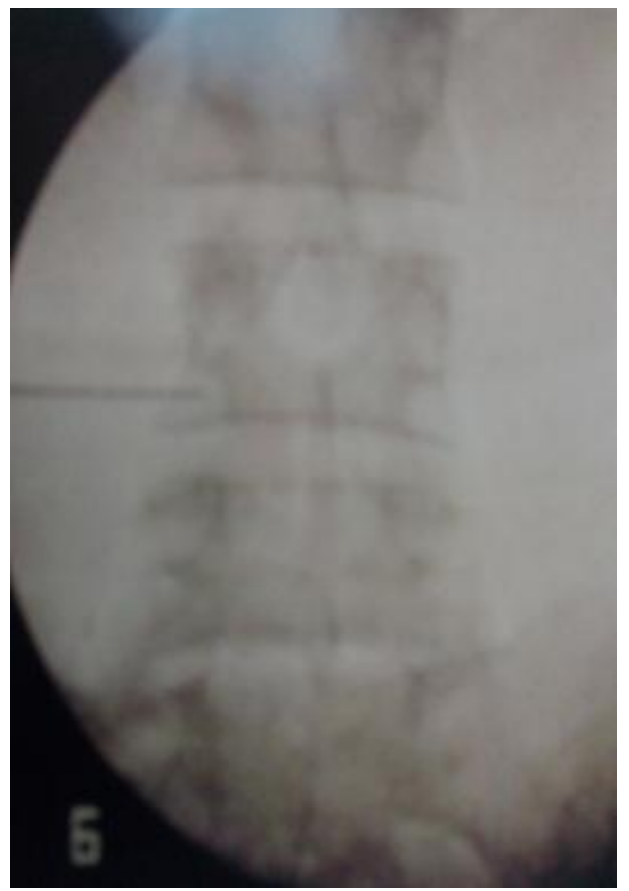

Fig. 1: Injection given Between L4-L5 (AP view) 


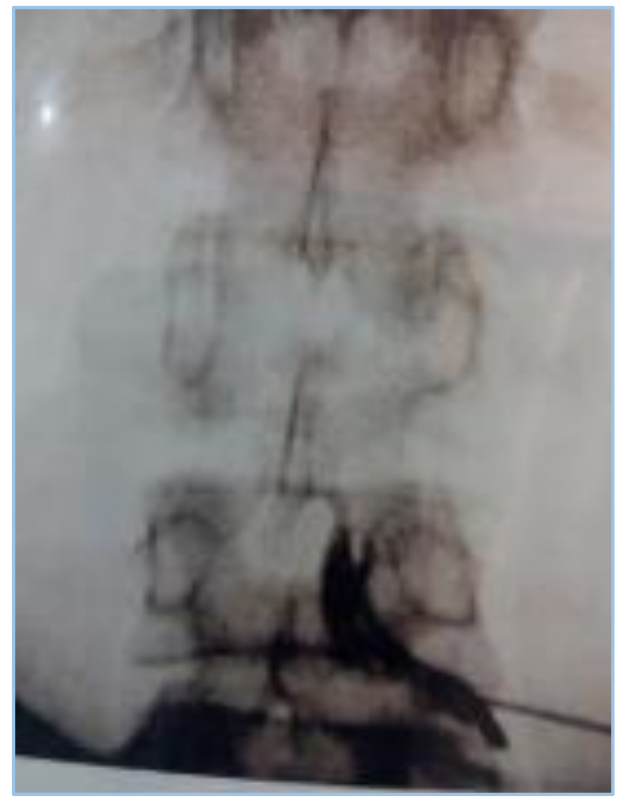

Fig. 2: After Injection of Dye

After the procedure, the patients usually were observed for numbness or any muscle weakness in the dermatome supplied by the injected spinal nerve. Any complication is followed up clinically and documented.

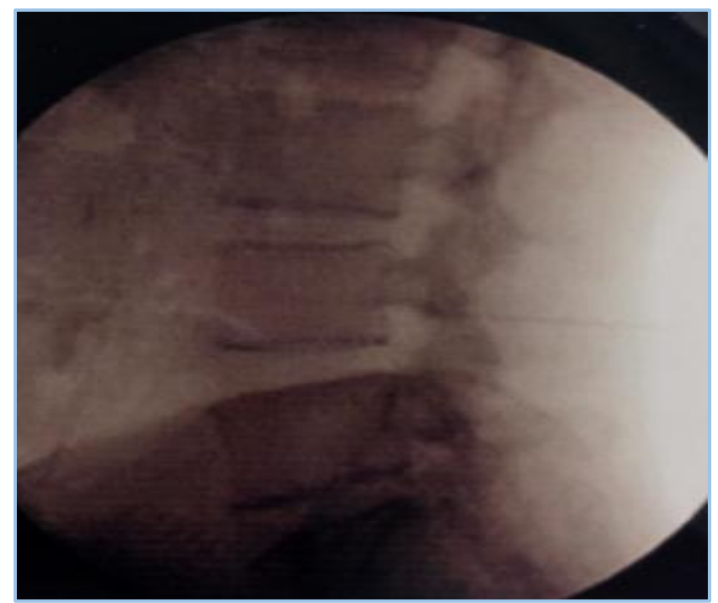

Fig. 3: Injection given Between L4-L5 (Lateral View)

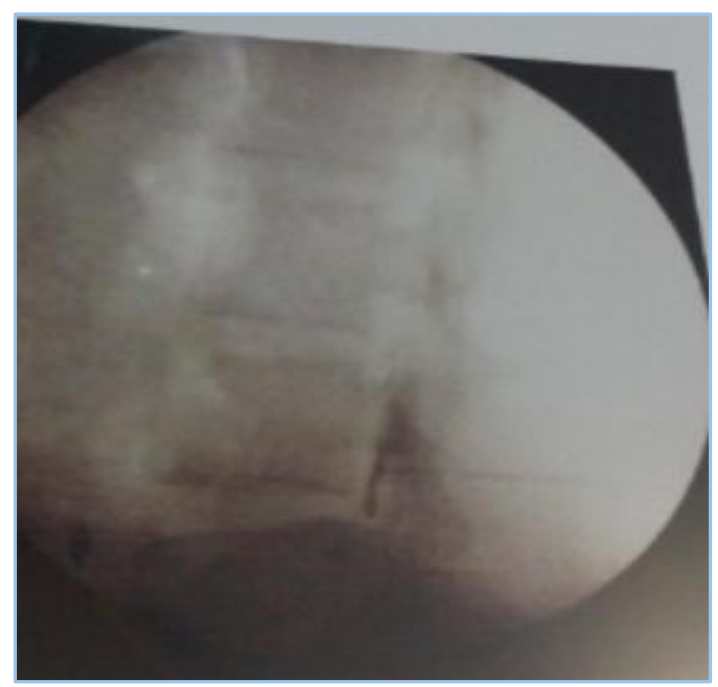

Fig. 4: After Injection of Dye

\section{Assessment and Followup}

Patients were assessed for complications clinically, immediately after the procedure and at follow-up of 1 week, 2 weeks, 1 month and 6 months following the procedure. Assessment was done on the basis of findings based on clinical examination.

\section{OBSERVATION AND RESULTS}

The study was conducted in the Department of Orthopaedics, SKIMS Medical College, Srinagar, from November 2012 to October 2014. A total of 110 cases were included in the study. The males were 53 (53\%) and females were 47 (47\%). The age distribution of cases is given in Figure 5.

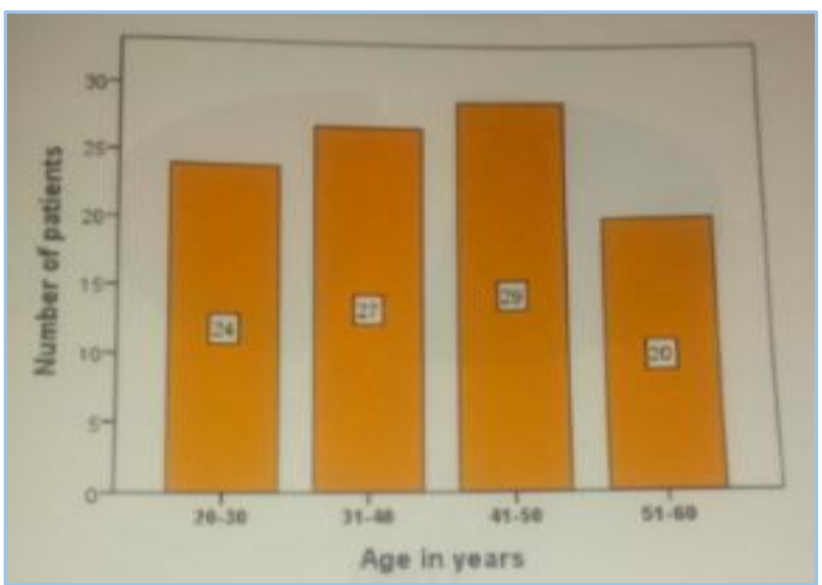

Fig. 5: Age Distribution of Cases

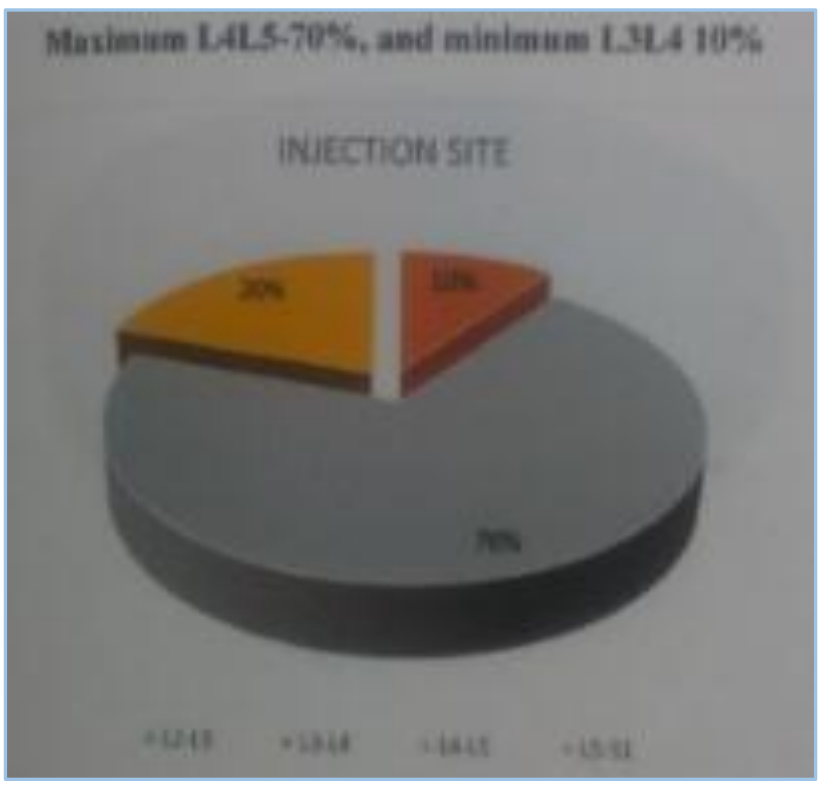

Fig. 6: Site of Injection

Figure 6 shows the distribution of site of injection with maximum being at the site of L4-L5 followed by L5-S1. The right-sided radiculopathy showed a preponderance over the left-sided radiculopathy with the right side having 59\% incidence and left side $41 \%$, which is shown as a graphic depiction in Figure 7. In our study, the maximum site of disc herniation was noted to be a lateral disc as is shown in the following Figure 8. 


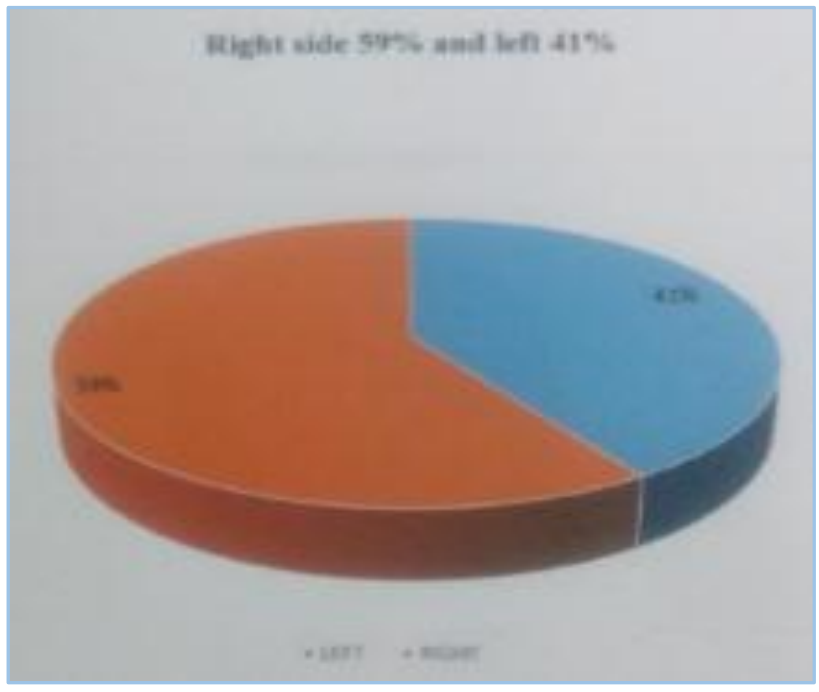

Fig. 7: Showing Preponderance of Right

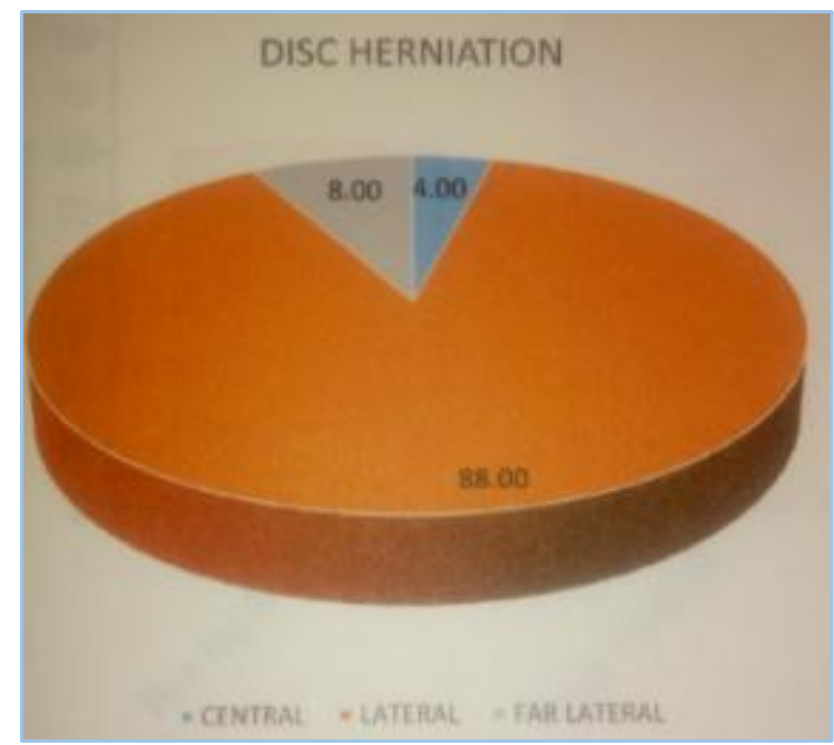

Fig. 8: Graph to depict the Presentation of Sided Radiculopathy. Disc Herniation Site

\section{COMPLICATIONS}

The complications were noted and are assembled in the following Table (Figure 9).

\begin{tabular}{|c|c|c|c|}
\hline $\begin{array}{c}\text { Sl. } \\
\text { No. }\end{array}$ & Complication & $\begin{array}{c}\text { No. of } \\
\text { Patients }\end{array}$ & Percentage \\
\hline 1. & Vasovagal reaction & 4 & 4 \\
\hline 2. & Infection & - & 0 \\
\hline 3. & Haematoma & - & 0 \\
\hline 4. & $\begin{array}{c}\text { Intravascular } \\
\text { injection }\end{array}$ & 5 & 5 \\
\hline 5. & $\begin{array}{c}\text { Nerve trauma } \\
\text { (Severe pain) }\end{array}$ & - & 0 \\
\hline 6. & Embolism & - & 0 \\
\hline 7. & Dural puncture & 2 & 2 \\
\hline 8. & Disc entry & 2 & 2 \\
\hline 9. & Urinary retention & - & 0 \\
\hline 10. & $\begin{array}{c}\text { Complications of } \\
\text { radiation exposure }\end{array}$ & - & 0 \\
\hline 11. & $\begin{array}{c}\text { Hypersensitivity } \\
\text { reaction }\end{array}$ & - & 0 \\
\hline \multicolumn{3}{|c|}{ Figure 9: Table showing the Complications Associated } \\
with the Procedure and their Incidence Rate
\end{tabular}

\section{DISCUSSION}

In our study, 100 patients were taken for TFESI in the age group of 20-60 years. The mean duration of low back pain with radiculopathy was 17 months.

There were a total of 53 males and 47 females, which is a male percentage of $53 \%$ and a female percentage of $47 \%$. This study shows that prevalence of low back pain with radiculopathy is more common in men because of their nonsedentary lifestyle in this part of the world as against the study of Hee Sung Jeong et al. (2007), which shows female dominance (106 males and 133 females; mean age 49.8 years; range 13-82 years of age)..$^{25}$

Our study also shows that the maximum site of injection was at L4-L5 followed by L5-S1. The right-sided radiculopathy showed a preponderance over the left-sided radiculopathy. The maximum site of disc herniation was noted to be a lateral disc.

\section{COMPLICATIONS OF TFESI}

\section{Vasovagal Reaction}

In our study, 4 patients out of a total of 100 patients (4\%) developed vasovagal reaction. This observation is in consonance with David J. Kennedy et al. (2013).19 They reported an incidence of $3.6 \%$ vasovagal reaction in their study. Another study done by Karman $\mathrm{H}$ et al. reported a vasovagal reaction in $8.7 \%$ patients. ${ }^{15}$

\section{Intravascular Injection}

In 5 out of 100 patients (5\%) intravascular injection occurred. This complication rate compares favourably with the study of Karman $\mathrm{H}$ et al. ${ }^{15}$ The incidence of intravascular injection in their study was 7.4\%. Intravascular injection was diagnosed on the basis of blood "Flash back" or aspiration of blood. 15

Recognition of intravascular uptake and contrast spread is needed to avoid inadvertent injection of medication into the vessels. Furman et al. (2000). ${ }^{16}$ reported an overall rate of $11.2 \%$ intravascular injection for lumbosacral region. The incidence of intravascular uptake with ILESI is reported by Sullivan et al. to be $1.9 \% .^{17}$

In the studies that reported the intravascular injections, no complications or adverse effects were found from intravascular, presumably intravenous injection of contrast, steroid or local anaesthetic. ${ }^{17,18}$ Theoretically, patients may experience temporary adverse reactions from systemic uptake of local anaesthetic. These problems include a range of minor symptoms like dizziness, tinnitus, disorientation, muscle twitching and metallic taste to major symptoms like seizures, unconsciousness and coma. Our patients did not encounter any such effects. ${ }^{17,18}$

\section{Disc Entry}

Disc entry was noted in 2 patients (2\%), which was noticed by the spread of medication to structures outside of the intended epidural target. Finn and Case, et al. (2005). ${ }^{20}$ recounted a case of disc entry as a complication of transforaminal injection. Hong JH et al. (2013). ${ }^{21}$ published the overall incidence of ID injection to be $2.4 \%$. Another study by Candido et al. (2010).22 revealed an intradiscal injection rate of $0.25 \%$. We did not encounter any loss in efficacy and have found excellent outcomes in cases by 
injecting around the spinal nerve after injection into the disc herniation.

\section{Dural Puncture}

Dural puncture was seen as another complication in 2 patients. We used cerebrospinal fluid flash back to recognize the complication of a dural puncture. This technique has been recommended by Goodman BS et al. (2007).26

\section{Nerve Trauma (Manifested by Severe Pain)}

Severe pain due to nerve trauma is another common complication during injection. We noticed this complication in 3 patients. Bogduk N et al. (2004) also reported this complication in their study without mentioning the percentage. ${ }^{27}$

\section{CONCLUSION}

Transforaminal epidural steroid injection is an excellent form of conservative treatment in management of low back ache with radicular pain. It is relatively safe, simple, economical and shortens the time of recovery from severe pain, avoids risks and is associated with insignificant rate of complications which are minor in nature.

\section{REFERENCES}

1. Frymoyer JW, Cats Baril WL. An overview of the incidences and costs of low back pain. Orthop Clin North Am 1991;22(2):263-71.

2. Vad VB, Bhat AL, Lutz GE, et al. Transforaminal epidural steroid injections in lumbosacral radiculopathy: a prospective randomized study. Spine 2002;27(1):11-6.

3. Silbergleit R, Mehta BA, Sanders WP, et al. Imaging guided injection techniques with fluoroscopy and CT for spinal pain management. Radiographics 2001;21(4):927-42.

4. Mclain RF, Frymoyer JW, Weisel SW, et al. Lumbar disc disease the adult and pediatric spine, philadelphia, pa: lippincott Williams and Wilkins, 2004;3rd edition:929-44.

5. Sitzman BT, Fenton DS, Czervionke LF, eds. Epidural injection. Image guided spine intervention. Philadelphia, Saunders, 2003;99-126.

6. Cohen SP, Bicket MC, Jamison D, et al. Epidural steroids: a comprehensive, evidence based review. Reg Anaesth Pain Med 2013;38(3):175-200.

7. Manchikanti L, Abdi S, Atluri S, et al. An update of comprehensive evidence based guidelines for interventional techniques in chronic spinal pain part ll: guidance and recommendations. Pain Physician 2013;16(2):S49-283.

8. Koc Z, Ozcakir S, Sivrioglu K, et al. Effectiveness of physical therapy and epidural steroid injections in lumbar spinal stenosis. Spine (Phila Pa 1976) 2009;34(10):985-9.

9. Luijsterburg PA, Verhagen AP, Ostelo RW, et al. Effectiveness of conservative treatments for lumbosaccral radicular syndrome: a syatemic review. Eur SpineJ 2007;16(7):881-99.

10. Boswell MV, Trescott AM, Datta S, et al. Interventional techniques: evidence based practice guidelines in the management of chronic spinal pain. Pain Physician 2007;10(1):7-111.

11. Lutz GE, Vad B, Wisneski RJ, et al. Flouroscopic transforaminal lumbar epidural steroids: an outcome study. Arch Phys Med Rehabil 1998;79(11):1362-6.
12. Gajraj NM. Selective nerve root blocks for low back pain and radiculopathy. Reg Anesth Pain Med 2004;29:243-56.

13. Riew KD, Yin Y, Gilula L, et al. The effect of nerve root injections on the need for operative treatment of lumbar radicular pain a prospective, randomised, controlled, double blind study. J Bone Joint Am 2000;82A(11):158993.

14. Derby R, Bogduk N, Kine G. Precision percutaneous blocking procedures for localising spinal pain Part ll: the lumbar neuraxial compartment. Pain digest 1993;3:17588.

15. Haktan Karaman, Gonul Olmez Kavak, Tufek A, et al. The complications of transforaminal epidural steroid injections. Spine 2011;36(13):E819-24.

16. Furman MB, Obrien EM, Zgleszewski TM. Incidence of intravascular penetration in transforaminal lumbosaccral epidural steroid injections. Spine 2000;25(20):2628-32.

17. Sullivan WJ, Willick SE, Chira-Adisai W. Incidence of intravascular uptake in lumbar spinal epidural procedures. Spine 2000;25(4):481-6.

18. Goodman BS, Lincoln CE, Deshpande KK. Incidence of intravascular uptake during fluoroscopically guided lumbar disc injections: a prospective observational study. Pain Physician 2005;8(3):263-6.

19. Kennedy DJ, Schneider B, Casey E, et al. Vasovagal rates in fluoroscopically guided interventional procedures: a study of over 8000 injections. Pain Med 2013;14(12):1854-9. doi:10.1111/pme.12241.

20. Finn K, Case J. Disk entry, a complication of transforaminal epidural injection-a case report. Arch Phys Med Rehabil 2005;86(7):1489-91.

21. Hong JH, Kim SY, Huh B, et al. Analysis of inadvertent intradiscal and intravascular injection during lumbar transforaminal epidural steroid injections, a prospective study. Reg Anaesth Pain Med 2013;38(6):520-5.

22. Candido KD, Katz JA, Chinthagada M, et al. Incidence of intradiscal injection during lumbar fluoroscopically guided transforaminal and interlaminar epidural steroid injections. Anaesth Analg 2010;110(5):1464-7.

23. Berman AT, Carbarino JL, Fisher Stand Bosacco SJ. The effect of epidural injection of local anaesthetic and corticosteroid on patients with lumbosciatic pain. Clinical Orthopaedic 1984;188:44.

24. Kepes ER, Duncalf D. Treatment of backache with spinal injections of local anesthetics, spinal and systemic steroids. A review: Pain 1985;22(1):33-47.

25. Hee Sung Leong, Lee JW, Kim SH, et al. Effectiveness of transforaminal epidural steroid injection by using a preganglionic approach. Radiology 2007;245(2):584-90.

26. Goodman BS, Bayazitoglu M, Mallempati S, et al. Dural puncture and subdural injection: a complication of lumbar transforaminal epidural injections. Pain Physician 2007;10(5):697-705.

27. Bogduk N. Lumbar medial branch blocks. Practice guidelines for spinal diagnostic and treatment procedures. San Francisco: International Spine Intervention Society, 2004;47-65. 